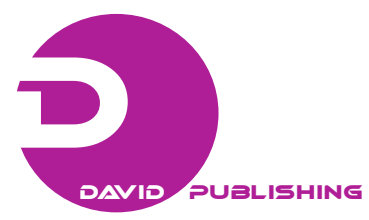

\title{
Architecture, Faith and Culture Antagonism or
}

\section{Harmony?}

\author{
Hassib Rehailia \\ Department of Architecture, Badji Mokhtar University, Annaba 23000, Algeria
}

\begin{abstract}
The relationship between architecture and faith has always been of great wealth. Faith as a way of life and social memory exercises a decisive influence on the shape of the construction environment. Yet this relationship is rarely analyzed. On a general level, one reason for this deficiency is probably due to the spread of the ideology of modernity. Given that modernity is implicitly secular, it does not prompt to understand faith in its relationship with other phenomena. It is the same for architecture. We believe on the contrary that the construction environment and the cultural aspect must interact and complement each other. When this is not true or only partially true, this results in user dissatisfaction, and refusal to engage and participate in the process of changing that environment. Many authors have tried to show explicitly the influence of Islamic thought on the social organization and the housing as well as the link between housing and identity, but its implications have not always been understood and transmitted concretely. One thing is certain: the ideological -symbolic-metaphoric sphere is the essence of architecture, as are the program requirements: functionality, distributivity, health of the environment and technology of construction. In this contribution we will address the thorny issue of cultural and religious influences on the choice of the morphology of the habitat and its components, and we will try to highlight the interaction between architecture, faith and culture through analysis of a Mediterranean type "House with Patio" as a particular architectural style, which has been enriched through the centuries by different cultures. Although the course of this typology in each of these cultures and at different times has not been the same, this has only strengthened the mission and spirit of the "Patio" until the appropriation of this model by the Arab-Muslim peoples who were able to incorporate the Islamic perception in this space.
\end{abstract}

Key words: Islamic Architecture, faith and culture, the traditional urbanism, Mediterranean cities.

\section{Domestic Spaces}

The Arab-Islamic culture has developed a representation of the very special place that has allowed its original identity. This spatial representation of the architectural framework is linked to living experience. It is all daily actions which constitute the appropriation of space by users. Thus, architectural or urban design would be pointless if we did not incorporate it in a study of living experiences, which give the space its temporal and spiritual evolution. The organization of the city in the Arab-Islamic world, is based on common concepts which are expressed differently depending on location, existing building materials, and economic and cultural development of

Corresponding author: Hassib Rehailia, PhD, lecturer, research fields: architecture and applied arts, health, email:Hassib.Rehailia@gmail.com. each site. The traditional and popular aspect of these constructions manifests itself through the effect of natural or cultural environment, as well as all architectural features, structural and functional whose hidden meanings we will try to dissect and decipher.

The traditional house is "inhabited" by memory. The memory is built into the physical structures and imaginary space. Home memory does not only rely on images of specific acts, but also on pictures of places and names of the lineage as a guarantee of social excellence. The domestic memorial inscription is socialized and based on the use of the space as it evolves through the interactions between domestic players. Home memory takes shape through fitting into the domestic group structures and relationships that drive the social universe which occupies space and reinvents it each day [1]. 
The "traditional" house was also, for travelers, writers or artists, a mysterious place, enigmatic and fascinating [2]. It has undergone multiple reflections, particularly as regards the relationship between physical structure and the religious and social organization of Islam and has also resulted in monographs of high quality [3]. There are many stereotypes, as outlined by A. Raymond, concerning the characteristics of the traditional house often described as belonging to a single model, invariable in space-time, isolated within the city, totally introverted, with a rigorous window on the outside and an exclusive opening on the inside with a patio. R. Ilbert [4] highlights the dangers using terms such as "Oriental”, "Islamic" or "Arab” city (fig. 1), as well as ideologies that underpin it. Thus, whether the city or home, it is more prudent to get rid of misconceptions and uncontrolled designations in order to grasp the specificity of each space in its context.

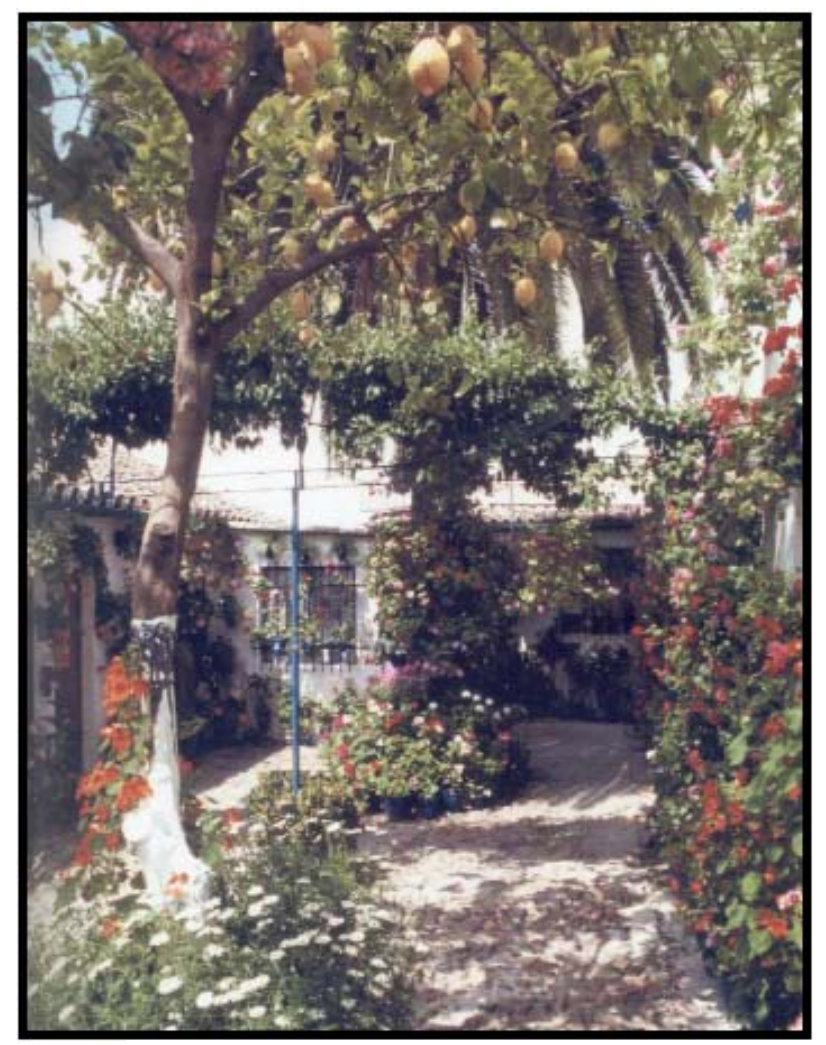

Fig. 1 A lemon tree in a Tunisian courtyard space provides shade in summer, while its size "high" passes the winter sun [5].

\section{Cultural Influences and Theories about the Shape of the House}

During the last decade, the relationship between domestic space and the society that uses it has been the subject of much discussion and research. Among these studies, the fundamental work of Pierre Bourdieu's on houses in Kabylia. In his research, he starts with a central reflection of placing the relationship between home and the ideological and symbolic parameters in correlations. For Bourdieu, the house is not only created by society, but should be considered as a framework in which children learn the rules that structure society, rules which themselves are created by society.

Bourdieu's study has caused other research dealing with villages in the Aures, the M'zab, and to a lesser degree the Atlas in southern Tunisia. This work has demonstrated explicitly the link between ideology, social organization and material homes. The attempt to define the organizational characteristics of the houses of the past and recent ethnography can help define boundaries in domestic spaces. This gives us different ways of looking at the effect of the cultural model on the shape of the house.

Suka Ozkan had the courage to devote an article to highlight the relationship between architecture, faith and culture. She insists that most cultural analysis have always sought to downplay the importance of religion, if they have not neglected it altogether, because of religion's political nature and standing in society: "The relationship between architecture or, more generally, between the building environment and faith has always been of great wealth. Faith as a way of life and social memory exercises a decisive influence on the shape of the building environment. Yet this relationship is rarely discussed. On a general level, one reason for this deficiency is probably due to the spread of the ideology of modernity. Given that modernity is implicitly secular, it does not prompt to understand the faith in its relationship with other phenomena. It is the same for architecture" [6]. It therefore seems important to 
explore the linkages between housing and social and cultural aspects of traditional societies. This does not mean that we neglect other influential factors on the choice of housing types and forms.

\subsection{Vocabulary Space}

The spatial vocabulary assigns names, in Arabic, to forms and spaces while emphasizing their content and their actions. This linguistic practice, both written and spoken, is strictly related to social and urban historical developments. The meanings of these names are often of great representative value of the image and the description we want to give space. The spatial and community vocabulary, linked to urban practices, allows us to better understand some socio-urban images and social behaviors.

We cite as an example in southern and eastern Mediterranean countries (predominantly Arab), the entire network from the alley until the dead-end represented by: darb (maze), the zoukak (narrow passage) The zankah (strangulation, alley which narrows along its path), the Khanka (suffocation, dead-end)...This illustration, which shows the correspondence between the perceptual image and its name, is a constant that we find both in urban and architectural domains. The many names designating the house and its components show the richness of this phenomenon. This variety of language adds to the space image as a temporal dimension that can not be perceived without prior training of the observer (Fig. 2).

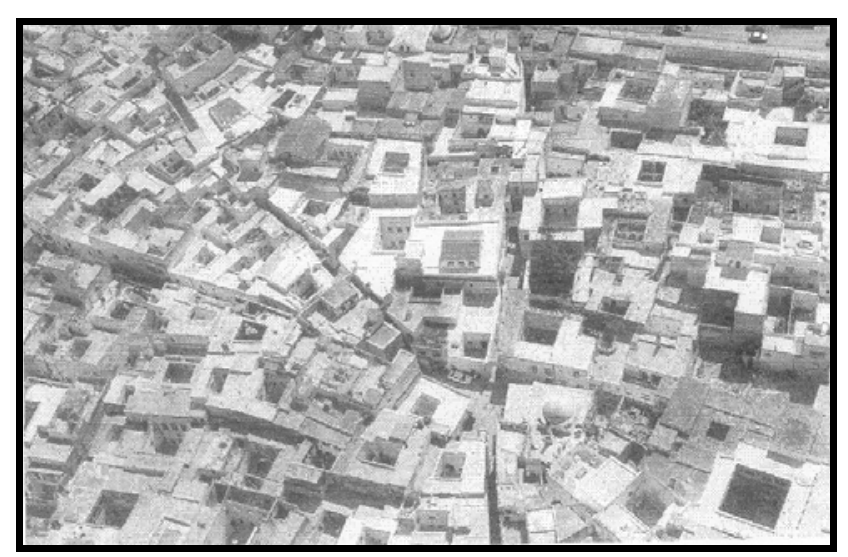

Fig. 2 Aerial view of the Medina of Tunis.

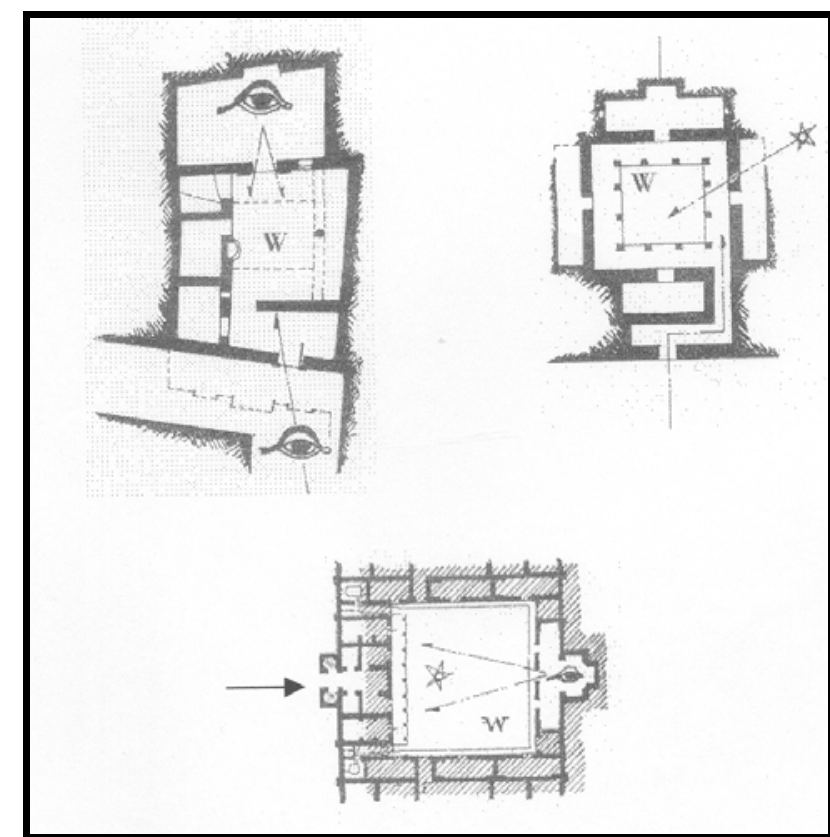

Fig. 3 Algiers: ground floor (staggered entry) [7].

The richness of the space-time vocabulary, combined with the architecture, provides a typology of spatial language that goes beyond the architectural formalism. It then creates new dimensions emphasizing understanding and images of space. This illustration which shows the correspondence between the perceptual image and its name is a constant that we find both in urban and architectural domains (Fig. 3).

\subsection{The Domestic Threshold, Symbolic of A Border}

The traditional planning is characterized by a long passage from private space to public space by introducing a "threshold" boundary that we try to describe $t$ first, then the status of the "liminal space" [8] and some of its symbolic and practical purposes, then its interaction rituals that are, according to E. Goffman, the rules of politeness and civility, how to behave, the of protocol-oriented postures, and finally crossing between modes of public space and private space, emphasizing the basic texts and authors who have addressed these issues.

The threshold (Alley, corridor, entrance hall, vestibule), important structuring element, is primarily an imaginary line of separation, as an internalized gap between two entities constituting spaces, inside and out. 
It is because there are fractures that these spaces take the quality of territories. The threshold is also a symbolic space in which to experience what binds the individual to the social body and in unties it. It marks the transition [9] between two completely different worlds. As an articulation point between home life and social life, in and out, the threshold is the symbolic "place" of the "in-between". As an articulation point, the threshold is also a "non-place" erected where the transition takes place, encounter and separation, thus a paradoxical element in that it allows and prohibits at the same time communication with others.

The social actor always generates the border and in return, the latter takes stage in the game of social reciprocity: Says Simmel about the symbolic role of the door: "Man ceases to be home when he walks past the door, and this means, of course, he breaks a part of eternity of the uninterrupted natural existence. But, if it is true that the shapeless limitation takes form, the boundaries he sets find their meaning and dignity only thanks to the symbol represented by the mobility of the door, with the ability to exchange at any moment this limitation in order to be free" [10].

It is A. Van Gennep who probably has best formalized the concept of "rites of passage". He showed that they all competed to mark a transition from one social state to another, a transition that introduces a time and a space to signal the difference between the prior and posterior state. Mr. Boughali defines rites of passage as both a manifestation of the end of a spiritual or social state and integration into another. These are "manifestations which are truly spatialized. It is in a space in its most material and terrestrial aspects that "the rites of passage" which rhythm existence integrate themselves” [9]. For P. Bourdieu, one must ask the theory of rite of passage questions about "the social function of the ritual and social significance of the line, the boundary, whose ritual makes lawful the passage, the transgression" [11]. Marking the passage with a line that establishes such a division of the social order, the ritual attracts the

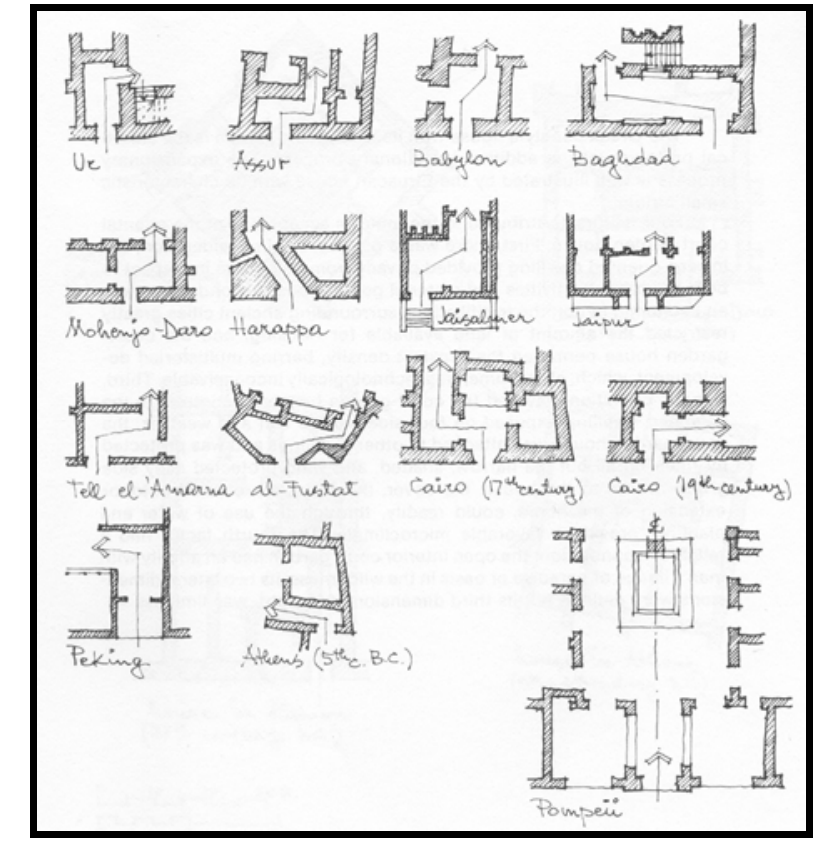

Fig. 4 Entries in different places and ages [12].

attention of the observer on the passage, while the more important, he says, is the dividing line that separates in a visible manner the before and the after.

In traditional homes, the entrance hall is usually set-up as a chicane and divided into two or three parts separated by a door (fig.4). Past the entrance, one finds himself in a stwan or sqifa, intermediate space where men wait for permission to cross the "border". A male visit results in the withdrawal of women from "visible" outer space. A space which generating first impressions and subjected to specific coding, it is also protected and part of a strategy of intimacy. The outer door remains open in general, a symbol of generosity and hospitality, referring to a social organization based on hospitality.

\section{Conclusions}

Despite their appearance as a basic courtyard house, in daily practice, the use of these forms gives Mediterranean houses a distinctly unique identity. Typographical analysis and spatial composition of homes have also shown that the design of the interior space of these homes is different. Indeed, the study of this model includes constant and variable features. We assert that these architectural and social practices are unchanging and reflect cultural and climatic influences 
of the region. They retain a considerable degree of adaptation in individual cases, because a theoretical model can not match the flexibility and spatial history of architectural practice, which is a major feature of Islamic tradition.

Muslim doctrine is at the origin of the design of these houses where the outside artifice is of little presence. This spirit is also reflected in the so-called Islamic architecture which gives an image of moderation, consistency and purity, with its maze of multiple spaces that allow both grouping and isolation, and finally with its judicious constructive systems and optimal use of materials.

Under the influence of Islamic thought, we notice that one of the characteristics of the urban Arab-Islamic morphology lies in the virtual absence of external marks of social distinction. This architecture features modesty and a moral ideal of equality, even if the interiors indicate clearly a search for distinction. This style is the result of mixing of three dominant factors: climate, religion and customs of its inhabitants, as well as building materials available locally.

The living space is a space "oriented towards ..." according to the reference culture. It is a constituent part of the cultural system. It gives codes of conduct and social representations. It is used to display what is prescribed and what is prohibited, especially around the categories of private and public. This opposition and its corollaries such as the oppositions inside/outside, familiar/foreign, near/far, male/female, could be considered as universal categories of human spirit that allow probing of the nature of the relationship that the resident establishes with his environment.

Arguably, the cultural unity of the Mediterranean cities was formed by the mixing of successive contributions influenced by social attitudes that prevailed in the area. The Arab-Islamic architecture is an architecture of forms, but it is not a formalist architecture. The comparison between Mediterranean cities reveals a number of basic elements common to all these architectures. These elements are also found in the Arab-Islamic architecture, such as the inlet chicane, the spatial articulations, the introverted court, zone separation, etc .... but each of these architectures has assimilated and interpreted these elements differently. A diversity of cultures is primarily determined in a global manner before being fragmented or amplified by the differentiated elements that have been joined together.

\section{References}

[1] Khalid Kajaj, La maison traditionnelle à Tatouan, Harmattan, Paris, 1999.

[2] J. C. Depaule, Figures de l'orientalisme en architecture, Revue du monde musulman et de la Méditerranée, Paris, 1996.

[3] G. Marçais, Les origines de la maison nord-africaine, Cahiers des arts et technique d'Afrique du Nord, $\mathrm{N}^{\circ}$, Paris.

[4] R Ilbert, La ville islamique: réalité et abstraction, Les cahiers de la recherche architecturale, $\mathrm{N}^{\circ} 10-11$, Paris, 1982.

[5] John S. Reynolds, Courtyards, Aesthetic, Social, and Thermal Delight, John Wiley \& Sons, Inc., USA, 2002.

[6] Suka Ôzkan, Foi, culture et architecture, dans Arch. \& Comport., Vol II, No. 3-4, pp. 187-192.

[7] André Ravéreau, La Casbah d'Alger, et le site créa la ville, Sindbad, Paris, 1989.

[8] F.Navez-Bouchanine, L'espace limitrophe entre le privé et le public, un no man's land? dans: Espaces et sociétés, $\mathrm{n}^{\circ}$ 61-62, 1991.

[9] M Boughali. La représentation de l'espace chez le Marocain illettré, Anthropos, Paris, 1974.

[10] G. Simmel, Pont et porte, L'Herne, les symboles des lieux, l'habitation de l'homme, $\mathrm{N}^{\circ} 44,1983$, p. 214. From Kh. Kajaj, Ibid.

[11] P. Bourdieu, Le sens pratique, Minuit, Paris, 1980.

[12] Norbert Schoenauer, 6000 years of Housing, Garland STPM, New York \& London, 1981. 